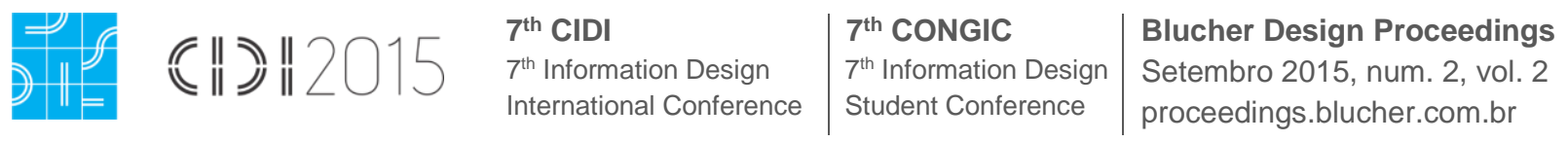

\title{
Holografia: Inovação e Metáfora de Interatividade na Comunicação e na Representação Ótica
}

\author{
Holography: Innovation and Metaphor of Interactivity in Communication and Optics \\ Representation \\ Ekaterina E. I. Barcellos, Marlon Mercaldi, Olympio J. Pinheiro, Galdenoro Botura Júnior
}

design, holografia, comunicação, interação humano-computador (IHC), lógica difusa "fuzzy"

O holograma proporciona uma realidade metafórica e metafísica compatível com o interesse da sociedade contemporânea por sistemas visuais e comunicacionais de impacto. Associado ao Design tem possibilitado um repertório de inovação diversificado que parte de hologramas poéticos e criativos até evoluções tecnológicas e interativas, culminando no inovador Microsoft Hololens. Para além da realidade virtual, a holografia se transformou em uma nova área de pesquisa e desenvolvimento essencial ao uso de imagens 3D. Sendo uma representação ótica que remete a elementos de ficção científica, esta complexa meta-estrutura propõe metáforas imagéticas e processos óticos inovadores que desafiam a lógica. A fusão entre Design e holografia tem permitido diferentes aplicações no campo físico, interagindo com o mundo real e possibilitando resultados que transpõe a realidade virtual, contribuindo em diferentes áreas, das artes à medicina diagnóstica. Tais aplicações permitem uma perfeita interação entre o corpo físico e $o$ holograma proporcionando um conceito comunicacional de experiência "ao vivo". Este artigo propõe apresentar um panorama do uso da holografia no Design, desde sua compreensão inicial atéo presente, demonstrando que o mesmo atende às expectativas pela inovação tecnológica em compasso com a evolução científica.

design, holography, communication, human computer interaction (HCl), fuzzy logic

The hologram provides a metaphorical and metaphysical reality compatible with the interests of contemporary society by visual and communication impact systems. In association with Design has enabled a repertoire of diverse innovation from poetic and creative to interactive holograms and technological developments, culminating in the innovative Microsoft Hololens. In addition to virtual reality, holography has become a new area of research and essential development to the use of 3D images. Being an optical representation that refers to elements of science fiction, this complex meta-structure proposes imagery metaphors and innovative optical processes that defy logic. The merger between Design and holography has allowed different applications in the physical field, interacting with the real world and enabling results implementing virtual reality, contributing in different areas, from arts to medical diagnostics. Such applications allow seamless interaction between the physical body and the hologram providing a "live" communication concept experience. This article aims to present an overview of the use of holography in Design from its initial understanding until the present, demonstrating that it meets the expectations for technological innovation in step with scientific developments.

E. E. I. Barcellos, M. Mercaldi, O. J. Pinheiro, G. Botura Júnior . 2015 Holografia: Inovação e Metáfora de Interatividade na Comunicação e na Representação Ótica . In: C. G. Spinillo; L. M. Fadel; V. T. Souto; T. B. P. Silva \& R. J. Camara (Eds). Anais [Oral] do $7^{\circ}$ Congresso Internacional de Design da Informação/Proceedings [Completos] of the 7th Information Design International Conference | CIDI 2015 [Blucher Design Proceedings, num.2, vol.2]. São Paulo: Blucher, 2015. ISSN 2318-6968, DOI 10.5151/designpro-CIDI2015-cidi_12 


\section{Introdução}

A holografia com seu efeito impactante se revelou uma ferramenta sofisticada e inovadora. Sua vantagem principal é a capacidade de reconstituir o tamanho, a forma e a tridimensionalidade de um objeto sendo possível perceber qualquer mudança, ainda que milimétrica em sua reprodução. Sua compreensão e aplicação se destinam a inúmeros produtos, inclusos os interativos, que se adequam a ambientes totalmente diversificados, resultando em uma tecnologia visual comunicacional de impressão metafísica, o que remete à imaginação do homem.

Desde o princípio das civilizações, o homem demonstrou a imprescindibilidade de se expressar por meio de imagens. No sentido antropológico, a cultura humana idealiza sua evolução no arcabouço imaginário; segue no sentido da concreticidade de suas ideias e de sua superação constante. Esta mesma perspectiva vale para a inovação das formas de comunicação e informação, em especial no último século. Corroboram desta visão Laplantine \& Trindade afirmando que "vivemos na atualidade a busca de novos caminhos que possam conduzir à compreensão e à superação da realidade" (LAPLANTINE, F., \& TRINDADE, L. 1997: 2). Pela visão de Pinheiro "(...) o computador poderia ser um modelo adequado para entender o funcionamento do cérebro humano, e os processos mentais poderiam ser estudados à luz da modelização computacional - é o modelo computacional da mente" (PINHEIRO, 2008). Uma visão do repertório imagético define que "imagens são construções baseadas nas informações obtidas pelas experiências visuais anteriores" (LAPLANTINE, F., \& TRINDADE, L. 1997: 2), reais ou imaginárias. A ficção científica protagonizou e antecipou a criação de algumas das mais conhecidas tecnologias visuais e comunicacionais que posteriormente foram executadas na prática. O desenvolvimento tecnológico atual confirma estas tendências que se revelaram há tempos na literatura de ficção. Pode ser citado o exemplo de Jules Verne, sugerindo tecnologias tidas como fantasiosas, que ao longo do tempo foram adaptadas e aperfeiçoadas com o progresso científico. A afirmação sobre a transferência de ideias tecnológicas decorrentes da ficção foi legitimada pelo físico Thorne, assessor de Carl Sagan, que em 2011 se tornou o consultor científico e produtor da ficção 'Interstellar' (MUNDOS FANTÁSTICOS, 2011). Há cerca de 40 anos atrás, na saga "Guerra nas Estrelas", pela ótica futurista que soma os conhecimentos da física à ficção sobre o rumo das civilizações, apresentava-se um holograma já no primeiro filme (princesa Leia), como relata Talbot (1991). É no mínimo instigante, que após décadas decorridas deste fato, diversos eventos artísticos tenham apresentado o uso da técnica do holograma idealizada por Lucas, 'ao vivo', em tempo real e de forma interativa.

É necessário entender o fenômeno da holografia e as diferentes visões de Paradigma e de Universo Holográfico. Segundo Wilber (2003) e Pribram (1994), tudo o que visualizamos em nosso mundo, o que nos rodeia e se estende ao universo, são imagens resultantes de sinais elétricos processados em nosso cérebro. A noção da holografia conhecida até o presente é a de uma reprodução tridimensional de imagens por laser, e segundo a qual, afirmam estudos corroborados pela comunidade científica: "todo o universo seria parte de um holograma gigantesco, uma imagem criada pela mente, contendo tanto a matéria quanto a consciência, num campo único" (TALBOT, 1991). A teoria do psicólogo Pribram em "Languages of the Brain" (1977) descreve que nosso acesso à memória e à consciência decorre de um processo similar à reconstrução de um holograma. Pondera que toda informação armazenada no cérebro é organizada em camadas relacionadas de forma semelhante ao holograma e por uma transformação semelhante à "transformada de Fourier", em "A Ordem Implicada" (BOHM, 2008). Ken Wilber, em seu livro "O Paradigma Holográfico e Outros Paradoxos" (1994), define holograma como sendo uma meta- estrutura mais abrangente no universo, que explica os fenômenos constituintes da realidade consensual. Há um crescente interesse pelo paradigma holográfico, e seu estudo se intensificou recentemente em função do surgimento de novas ideias na cosmologia, aprofundadas por Stephen Hawking (2010) e pela teoria conhecida como

Anais [Oral] do 7ํㅡㄹ Congresso Internacional de Design da Informação | CIDI 2015

Proceedings [Oral] of the 7th Information Design International Conference / IDIC 2015 
"princípio holográfico", desenvolvida por Susskind (2006), físico de Stanford. Estas teorias são decorrentes de estudos anteriores dos físicos Thorn e T'Hooft, prêmio Nobel de 1999.

Para Talbot (1991), em "Universo Holográfico", o físico Bohm e o neurofisiologista Pribram consolidaram a teoria do paradigma holográfico. A tese de Talbot indica quea "macro realidade" é percebida a partir deste fenômeno, de lógica difusa, que resulta numa nova representação ótica. Desta maneira é proposta "uma nova conceituação da matéria, inspirada no princípio da holografia" (TALBOT, 1991).

Quanto à etimologia, a palavra holografia dá pistas sobre suas propriedades, pois Holos em grego significa inteiro e graphos quer dizer sinal ou imagem - resultando que a holografia é a imagem por inteiro de um objeto. Conforme os dicionários Oxford Dictionary, Michaelis e Priberam, a raiz da palavra holon, hol-, sugere totalidade e integridade (do grego holos $=0$ todo) e o sufixo - on, usado costumeiramente no nome de partículas elementares, denota parte ou constituinte. O dicionário on-line worldreference.com (2014), acrescenta a definição do holograma como sendo uma imagem tridimensional (a laser) ou uma fotografia em três dimensões. Pela etimologia, o prefixo grego 'holo' quer dizer "todo, conjunto ou inteiro" e o radical grama $=$ escrito. Assim como grafos $=$ escrita, sinal, confirmado em alguns dicionários. Desta maneira, chega-se à mesma definição: a holografia corresponde ao "registro inteiro" ou o "registro total" de uma imagem. E a palavra Holografia deriva de Holograma.

Por estudos de Pribram (2014), confirmados ao longo das últimas décadas, experimentos e relatos publicados por Bohm (2008), ideias de Talbot (1991), por Hariharan (2002), e pelo conceito de hólons, de Wilber (1997), há consenso e comprovações suficientes de que o registro "total" de cada uma das partes possui as informações do todo. É fato, comprovado pelos mesmos, que um pequeno pedaço de um holograma contém as informações de toda a imagem, de um holograma completo, eque esta imagem poderá ser vista na íntegra a partir de um ângulo restrito, que permite parte da visualização, num processo oposto à ciência newtoniana, e que explora diferentes dimensões da realidade.

Como um paradigma da compreensão e percepção, a forma holográfica de estabelecer as relações do pensamento se modifica. DeFreitas (2014) lista estudos que convergem para um novo conceito de pensar, de uma forma espacial ao invés da forma linear. A mesma visão é corroborada por Talbot (1991). Como exemplo: o relógio e o calendário demonstram que tempo e coisas se movem para frente, linearmente, mas, a holografia nos mostra que "os tempos" (passado, presente e futuro) existem simultaneamente. DeFreitas (2014) é um holografista que faz uso dos hologramas há 30 anos podendo estudá-los mais proximamente. Cita que a visão mecanicista de Newton definia que "o que sobe, tem que descer". Mas a holografia modificou esta visão, pois nos ensina que para cima e para baixo são termos inúteis, que devem ser substituídos por: "para dentro e para fora" - ou "envolvendo e desdobrando". Na versão original: "While Newtonian physics states "what goes up, must come down", holography teaches us that up and down are useless terms that should be replaced by "inward or outward -enfolding/unfolding" (DeFREITAS, 2014). O holografista destaca que o holograma leva a uma evolução e uma nova ordem de raciocínio = "holográfica". ". Contextualiza que o mesmo ocorreu a colores sensu stricto (cores no sentido estrito), que apenas são aceitas como um fenômeno físico, não material (CAPRA, 1997). DeFreitas ainda compara que um holograma apresentado como uma obra de arte abstrata (que descreve esses princípios), ou um simples holograma estampado numa caixa de cereal, ambos contêm o "holo- view" (a visão holística integral da imagem integral), que está ali, visível e presente. Este aspecto de construção da memória é o ponto mais importante da compreensão do holograma e um paradigma complexo. Como define Morin (1982), um paradigma clássico corresponde à simplificação, a concepção simplificadora do universo, enquanto que um paradigma da complexidade incita a distinguir e fazer comunicar, ao invés de isolar e disjuntar, dando conta dos caracteres multidimensionais de toda a realidade.

Anais [Oral] do 7º Congresso Internacional de Design da Informação | CIDI 2015

Proceedings [Oral] of the 7th Information Design International Conference / IDIC 2015 
Uma das afirmações mais surpreendentes de Bohm é que a realidade tangível da vida cotidiana é realmente uma espécie de ilusão, como uma imagem holográfica. Subjacente a ela existe uma ordem de existência mais profunda, um nível de realidade mais fundamental e vasto que gera todos os objetos e manifestações do nosso mundo físico, do mesmo modo que um pedaço de filme holográfico gera um holograma.

Como um dos fenômenos mais complexos da consciência humana, a holografia definida por Bohm prova que o universo realmente emprega princípios holográficos em suas operações, sendo ele próprio uma espécie de holograma flutuante, gigante. Atualmente, a holografia vem sendo aplicada em outros níveis utilizando o código de padrões, que cria uma unidade digital distinta, e tornou-se uma tecnologia viável, podendo ser integrada a processos de reprodução de imagem, no dia a dia, em novas áreas de exploração, abrangendo aplicações em Design.

O museu do MIT (Massachusetts Institute of Technology Museum), fundado em 1861, conta com um grande acervo de hologramas. Possui a maior e mais abrangente coleção de Hologramas do mundo, incluindo Hologramas históricos. Preserva mais de um milhão de objetos, arquivos técnicos, desenhos, livros raros, gravuras, fotografias e filmes (M.I.T.Museum, 2015). Entre eles encontram-se projetos e pesquisas de Steven A. Benton, pioneiro no campo da holografia e das imagens 3-D. Benton foi o criador do Holograma do arco-íris (M.I.T Benton, 2003), sistema que é utilizado nos cartões de crédito atualmente. Ele teve vários de seus trabalhos holográficos expostos no Museu de Holografia de Nova York. Engenheiro de Harvard e cientista, foi diretor do CAVS (Advanced Visual Studies) no Laboratório de Mídia do MIT, e um dos responsáveis pela difusão e aplicabilidade da holografia (M.I.T. Benton, 2003). Patenteou diversas invenções na área da holografia, física ótica e fotografia e sua pesquisa rendeu os compósitos tridimensionais que têm sido utilizados nos diagnósticos médicos. Em sua visão "a intersecção entre ciência, arte e tecnologia é o que torna a holografia tão interessante" (BENTON, 1969 apud BELÉNDEZ, 2009), uma constatação válida até hoje.

\section{Evoluções Técnicas}

\section{'Fantasmagoria': a llusão antes da Técnica}

J.H. Pepper, precursor e criador do primeiro método de uso do holograma (séc. XIX), e por este motivo denominado "Pepper Ghost" - o "Fantasma de Pepper" (MEDEIROS, 2006). Teria afirmado que a concreticidade da realidade é somente uma ilusão holográfica, num insight da física quântica, já que a matéria existente é uma ilusão de concreticidade (CAPRA, 1996). O princípio se aplica também à suposição de que o design manipula a realidade, destacada por Flüsser (2007). Os efeitos metafísicos do holograma são tão surpreendentes que se assemelham a truques (a ponto de sustentar essa hipótese). Buscando o trajeto histórico do surgimento do holograma, há indícios de que foram inicialmente utilizados com esta finalidade. Como técnica ilusória, segundo a filosofia de Flüsser no livro "O Mundo Codificado", o que está por trás de toda técnica, toda arte e design, junto ao potencial criativo dos designers, se compara a um repertório de "conspiradores maliciosos" na capacidade de criar "armadilhas". E completa que é onde arte e técnica se unem numa nova forma de cultura; cultura esta, consciente e "astuta", pois cria dispositivos de "enganação" (FLÜSSER, 2007). Mas também destaca que o olhar do designer age como uma espécie de olhar-sentinela que se assemelha a um computador capaz de olhar para a eternidade e também de manipulá-la, modificando-a. Ora o designer é um enganador, ilusionista; ora o designer é o olhar-sentinela do futuro. Design e comunicação seriam segmentos de um fenômeno definido como codificação da

Anais [Oral] do $7^{\circ}$ Congresso Internacional de Design da Informação | CIDI 2015

Proceedings [Oral] of the 7th Information Design International Conference / IDIC 2015 
experiência. E por meio de "manipulações" e modificações do design, hoje, ao invés de compreender a realidade por teorias e modelos baseados na matéria, estaríamos projetando formas, para então atribuir matéria a elas e assim produzir "mundos alternativos" (FLÜSSER, 2007), confirmando teorias propostas por Capra (1997).

A "fantasmagoria" foi uma técnica de ilusão e arte criada na França no século XVIII. Aperfeiçoada no Período Científico do séc. XIX, foi introduzida com sucesso nos teatros de Londres em 1860 (MEDEIROS, 2006). Consistia no refinamento de técnicas arcaicas que utilizavam lanternas para projetar imagens envolvidas por cortinas de fumaça ou telas semitransparentes. Pepper desenvolveu melhorias no método utilizando espelhos e placas de vidro. Seu "Fantasma" impressionou frequentadores de teatro com efeitos que permitiam que pessoas vivas, ou objetos, se "materializassem" lentamente, surgindo como fantasmas em cena. O "fantasma" que gerava a ilusão era apenas um efeito da projeção da imagem de um ator localizado abaixo do chão do palco. $O$ ator jamais era visível como ser vivo, ou "matéria viva", somente como uma imagem "presencial" (refletido pelo projetor sobre um painel de vidro fora do palco), portanto, o efeito metafórico deixava a plateia atônita. Este truque envolve a questão filosófica da percepção e da ilusão, abordada na introdução; sobre definir o paradoxo do que é apenas visível, e do que é matéria, tido como real. A técnica foi sendo refinada pelo ilusionista e químico, e também pelo engenheiro inglês Henry Dircks com o uso de múltiplos projetores, às vezes montados sobre trilhos, permitindo a movimentação das imagens de forma dinâmica, criando efeitos de aproximação e distanciamento, do tipo zoom. As imagens, que apareciam "diante dos olhos", eram sobrepostas ao mundo real em tempo real, e quando passaram a interagir com atores reais e outros objetos, causaram grande impacto e sucesso.

Figura 1: Espetáculo com o efeito de "fantasmagoria", holograma de telas de gaze e refletor. Ilustração: "Dessin de Jakandler: Illusions d'optiquer- Les Spectres"; cena de teatro em Londres, 1862.

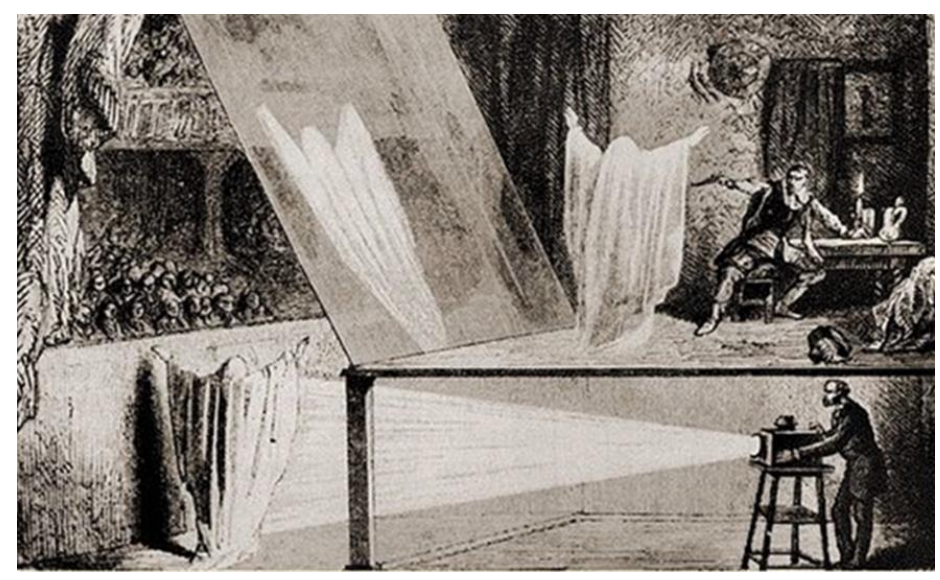

\section{Métodos Modernos}

A técnica do holograma foi alcançada e descrita por Gabor - Nobel em 1971, e o termo criado por ele. Inicialmente foi interpretada como uma fotografia tridimensional. Sua $1^{\underline{a}}$ holografia se concretizou em 1948, quando pesquisava uma forma de aumentar a nitidez do microscópio eletrônico. Não pôde aplicá-la na prática, porque para captar a dimensão de profundidade necessitava de um tipo de luz coerente, cujas ondas não se difundissem em todas as direções e que tivesse apenas uma cor. Ou seja, Gabor precisava de um feixe de laser, o que só seria descoberto em 1960. Mesmo assim, segundo Maier (2008) e Beléndez (2009), após a 
evento de Gabor, ainda durante a década de 50 , foram testados alguns hologramas com lâmpadas de mercúrio; a pesquisa nessa área foi do físico americano Baez.

A partir de 1962, Denisyuk, Leith e Upatnieks anunciaram a construção de hologramas com o feixe de laser (WILBER, 1994: 07) e, em 1965, o físico russo Denisyuk conseguiu, pela primeira vez, criar hologramas visíveis com a luz comum (MAIER, 2008). A partir desta data, o holograma se tornou uma nova forma de registrar a realidade.

Fig.2: Dennis Gabor e seu retrato holográfico, 1971, por Rhinehart - MIT Museum - Holography Collection from Museum of Holography (extraído de Beléndez, 2009).

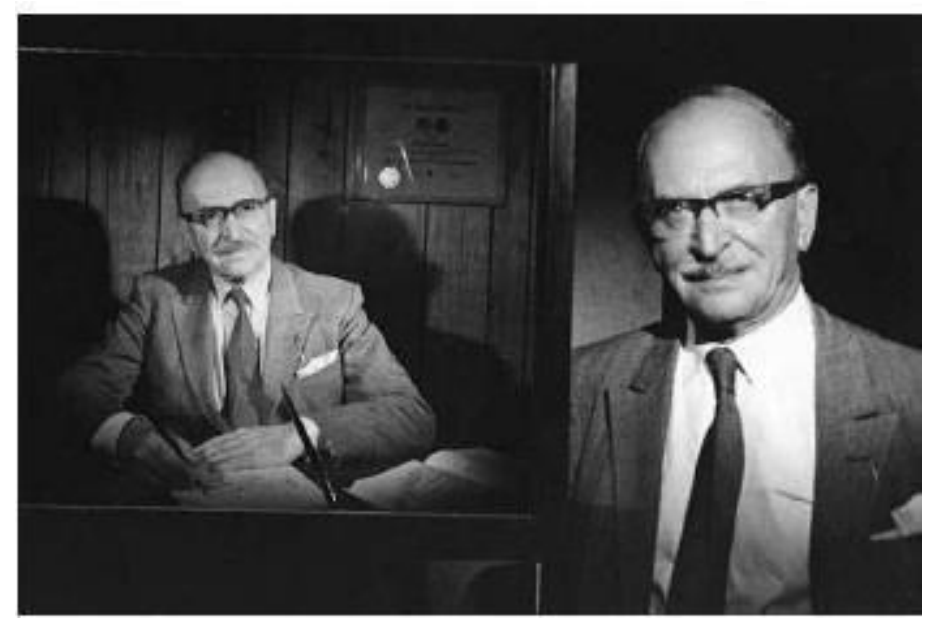

Há cerca de três décadas, em meio a um Congresso da Sociedade Ótica dos Estados Unidos, os físicos Leith e Upatnieks apresentaram, ao vivo, um holograma de uma locomotiva; todos pensavam tratar-se de ilusão ou truque, pois era inaceitável a possibilidade da materialização de objetos no espaço.

Para se obter um bom holograma, o sentido da holografia é o da reconstrução e da integralidade da imagem. O método inicial para sua "produção", segundo experimentos de Bohm, consistia em banhar o objeto-origem com um raio do tipo laser, pois a construção de um holograma necessita de uma fonte de luz laser, para a iluminação do objeto que se pretende registar. Em seguida, tira-se uma foto deste holograma. Segundo Pessoa Jr, no que se refere à sua aplicação, a técnica de projeção de um holograma consiste principalmente do armazenamento tridimensional de todas as informações de uma imagem. Uma das maneiras de reproduzi-la é gravar o holograma por um feixe de luz do tipo raio laser, e dividi-lo em dois componentes. Um componente incide sobre o objeto tridimensional e é refletido na direção de uma placa fotográfica. Depois, outro feixe de laser é aplicado, mas fora do alcance do primeiro jato. É gerado o reflexo da imagem, pois o outro componente do feixe de luz será utilizado como referencial para interferir com o primeiro na chapa fotográfica. Obtém-se então a imagem 3D plana. DeFreitas (2014) explica que a escolha acertada dos feixes de luz determina sob todos os aspectos a melhor qualidade de um holograma. Ao receber todo o espectro de luz, em vez de apenas uma banda, o holograma pode ser visto em todas as cores do arco-íris. Mas para alcançar esse efeito sacrifica-se a perspectiva tridimensional vertical. Em consequência, ao ser examinado de cima para baixo, ou de baixo para cima, o holograma colorido perde a dimensão de profundidade. A descoberta do movimento foi produto do trabalho de muitos cientistas, mas ficou conhecida graças ao físico americano Lloyd Cross (BELÉNDEZ, 2009). 
O fenômeno da holografia é uma metáfora do arquétipo da totalidade, e o desenvolvimento do processo forma "metáforas holográficas", que abrangem diferentes áreas do conhecimento (MAIER, 2008). Conforme Maier, o padrão de integralidade na holografia é óbvio, considerando-se ideias básicas da holografia óptica ao longo da história, estando este padrão ligado às expectativas modernas de novas tecnologias. Atualmente, os hologramas estão inseridos no dia a dia como os hologramas dos cartões de crédito e notas, que, em geral, são gravados e reproduzidos em película fotográfica, películas plásticas bidimensionais especiais ou em poliéster metalizado (hologramas impressos). Conforme Daibert (2014) e Beléndez (2009), esta é a mesma técnica aplicada em CDs, jogos e uma variedade de produtos para sequenciar a unidade original de cada um. Os autores, e Hariharan (2002), afirmam que é importante destacar claramente a diferença da holografia e da fotografia, já que são constantemente confundidas, mas são técnicas totalmente diferentes, que se baseiam em princípios óticos distintos, possuindo também propriedades físicas completamente diferentes. Em suas pesquisas descrevem que o sistema da holografia consiste em gravar uma infinidade de pontos de eixos distintos de uma imagem, formando um padrão a partir do qual o cérebro reconstrói o original, com o efeito tridimensional. Usa-se o registro de diferentes padrões de interferência de luz, que podem gerar ou apresentar as imagens em três dimensões. Ao se variar o ângulo de iluminação, eles registram informações diferentes. Assim, um holograma pode arquivar 10 mil vezes mais dados do que os discos e fitas dos computadores eletroópticos. Quando os dois feixes de luz se cruzam, as ondas interferem umas com as outras. Onde as cristas das ondas se encontram, forma-se luz mais intensa; onde uma crista de um feixe encontra o intervalo de onda de outro, forma-se uma região escura. É por isso que o filme depois de revelado não mostra uma imagem, mas um padrão de faixas ou anéis claros e escuros. Para visualizar a imagem no filme, usa-se o mesmo laser com que se gravou o objeto. Atrás da chapa fotográfica, se formará, então, uma imagem que poderá ser vista de vários ângulos como se ela fosse tridimensional.

Esta é a razão pela qual se compara o holograma a uma 'janela'. Se for parcialmente tampado ou cortado, a imagem atrás ainda será visível como pelas frestas de uma cortina. $O$ sistema mais moderno, difundido desde o início deste século, foi desenvolvido por Uwe Maass, um processo óptico chamado Musion Eyeliner, que é um sistema inovador de projeção de propriedade de alta definição de vídeo; permite a projeção de imagens virtuais quase 'flutuantes' (UWE MAASS, 2014). É uma forma de projeção de vídeo para criar a ilusão de tamanho natural, de imagens 3D em movimento e em tempo real. As imagens do sistema são imagens em três dimensões, mas projetadas como imagens bidimensionais (2D/3D) em um cenário 3D. A mente do público participa criando a ilusão de 3D, ou seja o efeito da totalidade. Isso significa que os custos de produção são mínimos, precisando apenas da lente da câmera para as filmagens e um projetor para a reprodução. Os materiais mais usados neste processo são películas especiais transparentes com propriedades refletoras semelhantes ao vidro semiespelhado. O delineador Musion, tem vantagens sobre o vidro, pois capta as partículas e as ondas de luz, que possam ser representadas em 3D e integradas à imagem (UWE MAASS, 2014) (disponível em www.musion.co.uk/uwe-maass-on-cnn).

Este sistema de projeção holográfica modificou as formas de utilização dos hologramas permitindo uma maior variação de aplicações em design, artes e comunicação.

\section{Holografia, Arte e Design}

\section{A Poesia das Esculturas de Luz}

O atrativo da holografia é a possibilidade de uma representação tridimensional, não submetida à restrição de tipos de elementos, físicos ou materiais. Porém, a dificuldade inicial na compreensão do uso da holografia retardou seu uso. Somente após os anos 70 voltou a ser

Anais [Oral] do 7º Congresso Internacional de Design da Informação | CIDI 2015

Proceedings [Oral] of the 7th Information Design International Conference / IDIC 2015 
explorada, principalmente em sua característica de fusão entre arte, ciência e tecnologia (BENTON, 1969 apud BELÉNDEZ, 2009). A estética holográfica foi então desenvolvida por designers e artistas. Uma maior exploração técnica determinou as versões em cores e com movimento, características que levaram os hologramas no início da década de 70, como expressão artística e inovação, às galerias de arte. Alguns de seus expoentes foram os artistas Benyon (UK), Berkhout e Casdin-Silver (EUA); o hológrafo Moysés Baumstein (BR); o artista e designer Júlio Plaza (BR); os poetas Augusto de Campos, Haroldo de Campos e Décio Pignatari (BR); a artista japonesa Setsuko Ishii, entre outros.

O artista plástico Moysés Baumstein participou de uma exposição coletiva denominada "A Visão do Artista - Missões 300 Anos" realizada no Museu de Arte de São Paulo. A 1a exposição brasileira de hologramas (1981) foi no pavilhão da Bienal em São Paulo, e dela se originou a primeira sala de exposições dedicada à holografia no MIS - São Paulo.

Durante a década de 80, Baumstein produziu e expôs hologramas artísticos em diversos museus e instituições no Brasil e no exterior. Em 1982, desenvolveu em seu laboratório técnicas próprias de exposição e revelação, de grande impacto visual e qualidade. Em 1987 montou um segundo laboratório em São Paulo voltado à produção holográfica artística e comercial. No total foram produzidos mais de 300 hologramas em seus dois laboratórios.

Fig. 3: Artista Setsuko Ishii: Self portrait: Body with Fabric 2. Multi color Multi-channel hologram (2000-2003) Fonte: http://www.absolutearts.com/ . Acesso em 02/03/2015.

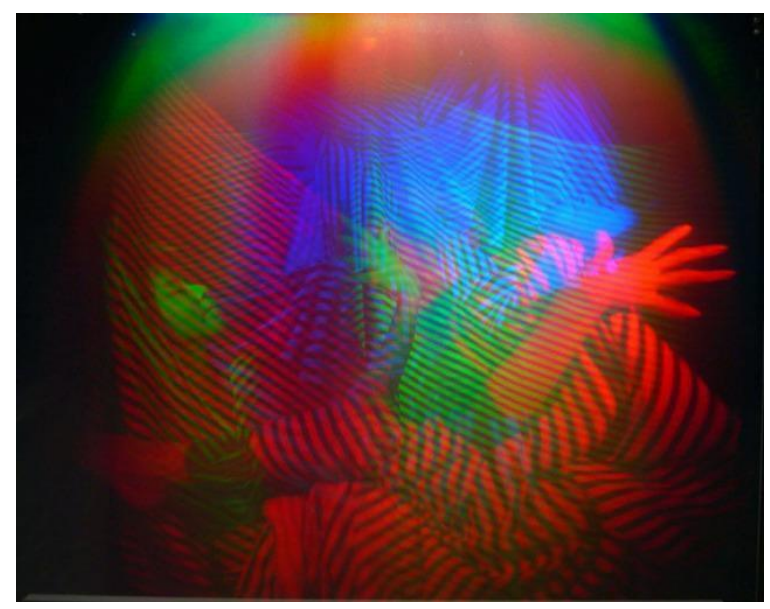

Fig. 4: O Arco-íris no Ar Curvo - Julio Plaza, Moysés Baumstein, Registro fotográfico Sérgio Guerini/ltaú Cultural. Acesso em 06/03/2015.

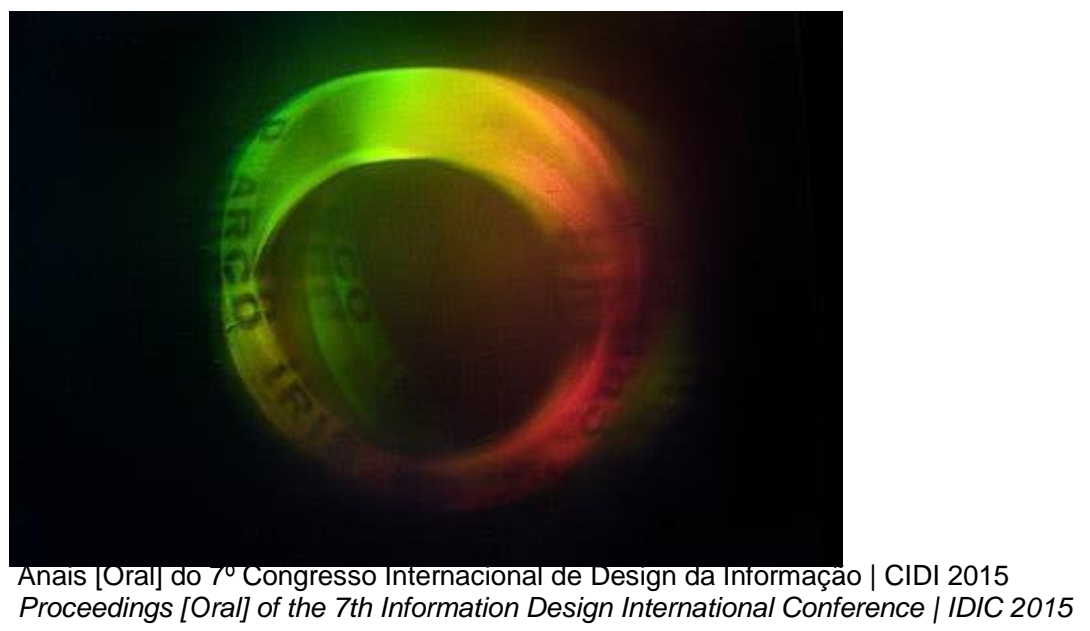




\section{Holografia no Design Moderno e Contemporâneo}

Como método de representação ótica, a holografia tem sido estudada pelo aspecto metafórico, e aplicada a sistemas do tipo Interação Humano-Computador (IHC) obtendo resultados práticos para projetos de interação com a aplicação de design e engenharia das interfaces humanas.

A técnica da holografia permitiu, para muito além da arte, que fossem criados sofisticados sistemas de análise de materiais e armazenamento de dados, já que um pequeno pedaço de um holograma contém as informações de toda a imagem do holograma completo, onde um ângulo restrito permite parte da visualização e condensa todo o restante.

Desde o final da década de 80 , há diversos hologramas artísticos, retratos holográficos e hologramas coloridos em lojas de presentes, livros, museus, em cartões ou selos postais; milhões de exemplares de livros e revistas circularam pelo mundo com algum tipo de holografia impressa. Brinquedos e cereais infantis das marcas Hasbro e Purina, usaram hologramas em suas embalagens. Os hologramas de segurança são um negócio de alcance global, e a Mastercard foi a precursora na inovação dos cartões de crédito com logotipos Holográficos; hologramas são usados para impedir sua falsificação devido ao fato de ser praticamente impossível imitar um holograma e para garantir a sua autenticidade e distingui-la de imitações (SUPER INTERESSANTE, 1988). Os hologramas diversificaram sua aplicação e ao final dos anos 80, a revista Super Interessante (1988) listava inúmeras outras aplicações do holograma, aumentando a cada década. Na Itália, um grupo de hológrafos começou a utilizar uma técnica, chamada interferometria holográfica, na restauração de quadros. Em museus de Paris e outros da Europa os hologramas já substituíram algumas relíquias e obras reais. No mundo todo foram instalados os dispositivos óticos holográficos para caixas registradoras de supermercados, que lêem os códigos de barra impressos nas embalagens. Nos Estados Unidos, hologramas foram usados no aproveitamento da luz solar ou artificial em estufas, hotéis e escritórios, para economizar energia elétrica. A joalheria Cartier, na 5a Avenida de Nova York exibiu uma pulseira cravejada de brilhantes em holograma. Na Inglaterra, a indústria ótica lançou lentes de contato holográficas bifocais. Os alemães decidiram construir o primeiro microscópio eletrônico de holografia de alta resolução. A integração da holografia em ambientes arquitetônicos é cada vez mais favorecida, confirmando uma tendência pelo aprimoramento da técnica na obtenção de hologramas de grande formato, mais complexos e raros (Beléndez, 2009). Por fim, o uso da holografia pode ser constatado no espectro eletromagnético e através de imagens infravermelho, e com radiação ultravioleta, havendo previsão de que brevemente será possível substituir a radiografia convencional pela imagem holográfica, com precisão de detalhes (BELÉNDEZ, 2009). Em 2015, a Microsoft apresentou a possibilidade de interagir por meio de hologramas com o lançamento do HoloLens. O Design do produto vai além das imagens bi e tridimensionais, utilizando os movimentos e as capacidades inerentes ao elemento real, simuladas no corpo 3D, não físico. Isso permite aos designers e usuários uma infinidade de novas interferências, de forma que haja uma hiper-realidade no protótipo imaterial obtido num processo que, no campo virtual, gera uma troca aplicável ao campo real (HOLOLENS, 2015).

\section{Interação e Design 3D em tempo real}

O foco do estudo avança para a interface do holograma tridimensional interativo. O novo escopo de aplicações situa-se em obter a visão tridimensional de pessoas e outros elementos registrados por holografia interagindo ou recebendo interações, em escala de reprodução real das proporções; neste ponto os aspectos antropométricos e ergonômicos são determinantes na perspectiva e no resultado, priorizados pelo design hiper-realista.

Anais [Oral] do 7º Congresso Internacional de Design da Informação | CIDI 2015

Proceedings [Oral] of the 7th Information Design International Conference / IDIC 2015 
Estas interfaces têm como enfoque reproduzir imagens em um novo contexto que substitui o real, e este deve ser suficientemente concreto para ocupar o lugar do elemento real. A aplicação de ergonomia com relação à escala de projeção deve buscar proporções reais, compatíveis com a posição e a perspectiva observadas. Esta aplicação se situa na necessidade de interagir com a projeção em tamanho real ou adequado, concretizando a semelhança com a consciência da imagem verdadeira, validando a interação. Versões totalmente distintas surgiram a partir do domínio das técnicas apresentadas do holograma saindo do campo das artes e dos museus. O aprimoramento do sistema de Pepper e Dircks foi manipulado por diversos cientistas e engenheiros eletrônicos até chegar ao método patenteado por Uwe Maass (1995), que aplicou a tecnologia digital com sucesso no Musion Eyeliner 3D. A evolução destes sistemas para eventos ao vivo, em tempo real, se baseia no anseio do público que deseja ver ou relembrar seus ícones e algumas simulações de imagens holográficas que remetem a apresentações ainda ativas na memória e na identificação com ídolos. Outras simulações são construídas acrescidas de novos elementos ou locais, como no caso dos hologramas que surgem acompanhando outros artistas, cantando e/ou dançando, em duetos, e em circunstâncias não realizadas em vida. Neste formato se alcança o objetivo do inédito, 0 impactante na estratégia do serviço ou do produto. No caso, algo que não faz parte do repertório da memória registrada pelos fãs.

Essa característica desperta ainda maior interesse, pois dá uma qualidade única ao espetáculo. A aplicação impactante do sistema tipo 3D Musion (utilizado por outras empresas com variações de técnica e nomenclatura) cria uma quase presença histórica, memorável, que se reafirma com a interface da imagem projetada com o holograma. Destacam-se os shows criados para a banda virtual Gorillaz (2006), e de alguns cantores (in memoriam) como Tupac (2012), no Coachella Music Festival, apresentado em interação, ao vivo, em tempo real com os artistas Dr. Dre e Snoop Dogg.

Figura 5 - à esq., "Tupac Hologram”, Coachella, 2012- holograma interativo com o rapper Snoop Dog - sistema Musion Eyeliner - adaptado de <http://www.youtube.com/watch?v=TGbrFmPBVOY>; à dir, descrição técnica do holograma de Tupac: Graphis by Roxanne Palmer for the International Business Times. Acesso em 15/04/2014.
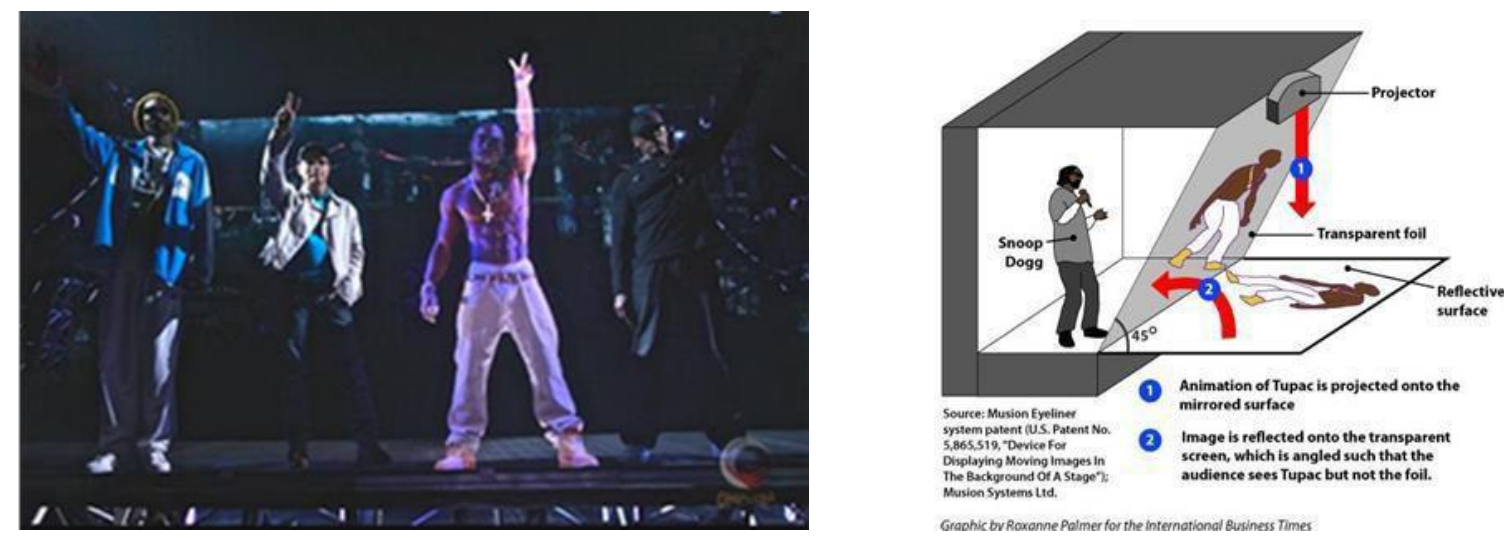

A lista de shows e eventos utilizando este tipo de técnica, após uma $1^{\text {a }}$ apresentação para a Swarovski em 1995, tornou-se infindável, no exterior e no Brasil. A holografia gerou também os conhecidos "ídolos" japoneses denominados "Vocaloids". O Japão tem demonstrado uma forte preferência por este tipo de apresentação com a criação destes artistas/cantores totalmente virtuais. 
$\mathrm{Na}$ área acadêmica o sistema Uwe Mass inovou em suas plataformas para que palestrantes, professores e médicos utilizassem suas holografias interativas ao vivo, em congressos e eventos, com o objetivo de "ministrar" palestras e cursos. Em alguns eventos o palestrante chega a ser totalmente substituído por seu próprio holograma, sem a real presença. Qualquer pessoa pode interagir com um entrevistado, em um holograma em tempo real ou previamente gravado. No sistema life sized hologram = holograma em tamanho real, um palestrante real pode expor informações e dados num método holograma Power Point 3D, e em seguida voltar a interagir com um holograma de uma pessoa participante. São possíveis multifunções dentro do mesmo projeto. Uma das mais promissoras aplicações atuais do holograma decorre do fato de se assemelhar a uma clonagem do objeto real. Este aspecto gerou o interesse para experimentos e aplicações recentes na área da medicina. Neste caso, a cópia holográfica do original (órgão do corpo humano) é fundamental para avaliar diagnóstico, intervenções e resultados aplicáveis; a holografia entra também como complemento dos raios $\mathrm{X}$ na área médica. A área diagnóstica e cirúrgica da cardiologia tem inovado técnicas e possibilitado avaliar análises de fluxo circulatório, e possíveis incisões cirúrgicas virtuais, por meio da manipulação das imagens pela holografia interativa 3D.

Figura 6 - "From Science Fiction to Science Fact", introduzindo a holografia médica ao vivo - Interactive Live Holography - the world's first 3D holographic display and interface system, initially for medical imaging applications, adaptado de http://www.realviewimaging.com.

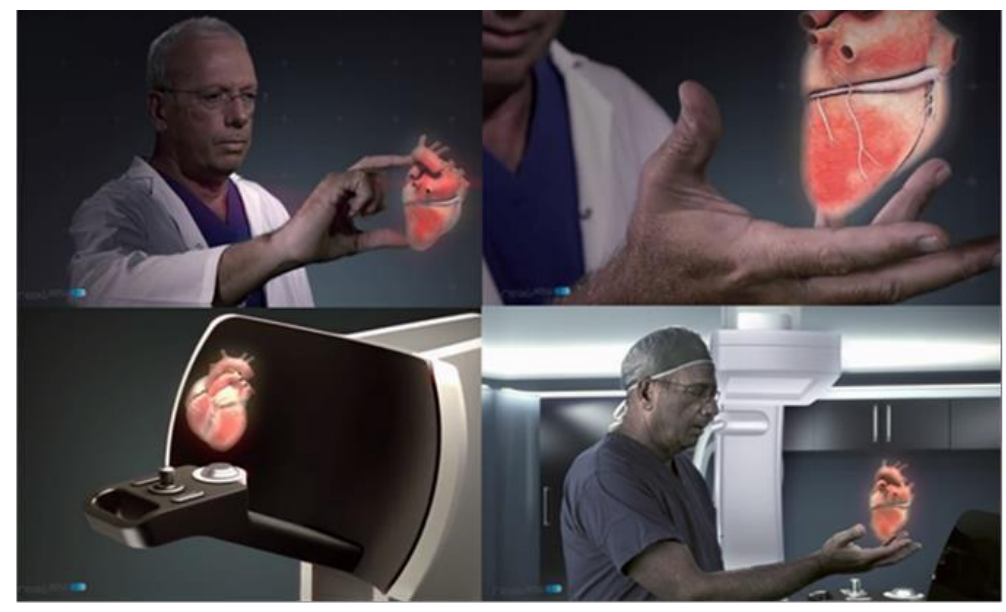

Numa nova proposta, o mais recente e inovador produto que associa Design e holografia se destina a outra uso. É o "computador holográfico" Hololens da Microsoft, apresentado no início de 2015. Reúne as evoluções e pesquisas anteriores, e se aproxima ainda mais do usuário final, com finalidades iniciais de lazer e diversão. Utiliza um dispositivo do tipo visor que tem conexão com um processador holográfico (Holographic Processing Unit ou HPU). É resultado dos desenvolvimentos decorrentes do holograma interativo, com uma pitada da variante utilizada nos vocaloids, pois é um sistema inteiramente voltado a interpretar gestos e vozes, permitindo criar, acessar informações, e entretenimento, e gerar novas formas de comunicação.

\section{Conclusão}

Conforme afirmações de Morin (1990), Pribram (1977; 1994) e Bohm (1994), o holograma estabelece a relação da totalidade, relacionada à interpretação do mundo moderno em sua complexidade. Decorridos cerca de 70 anos desde sua reprodução inicial, a holografia demonstra um futuro de crescente relevância. A aplicabilidade do holograma é bastante variada pelo caráter "presencial" não material. Para transpor partes do universo holográfico a uma 
aplicação interativa é necessário que a tecnologia alcançada seja apoiada por projeto de design, antropometria e ergonomia, que possibilitem o hiper-realismo necessário, na interação, no momento exato da projeção. O design adaptado ao estudo ergonômico configura características intrínsecas e demonstra que é possível lidar com assuntos bastante complexos ou controversos, de impacto emocional evidenciado.

As imagens em 3D exercem fascínio sob a forma virtual, especialmente em situações que possam se sobrepor à realidade e à logica. Isso se intensifica quando esta "não realidade" consegue compor ou impor cognição de "presença", aceita pelo cérebro como concreta e de forma convincente, trabalhando com a memória e a ligação neural. É perceptível o interesse pelo resultado na aplicação do design em holograma. A busca essencial de resultado satisfatório com o uso do holograma se concentra em: 1) constatar a concreticidade e a inovação de um projeto factível que acrescente elementos importantes e se sobreponha aos já conhecidos como desenvolvimento científico; 2) o design se apresente de forma impactante; 3) o projeto alcance um nível de transferência de imagem surpreendente, substituíndo o objeto físico por um virtual de efeito e resultado "real".

A "presença" virtual concreticista cria uma aceitação dentro do arcabouço cerebral, e se complementa pelas interfaces e aplicativos interativos, que determinam o nível de sucesso que o projeto consegue obter. Sem dúvida o interesse pela holografia vem ganhando dimensões multidisciplinares. É fato que a comunidade científica tem aceitado a relevância dos hologramas comprovada nas recentes descobertas da ciência e da física. A aplicação do holograma, desde as simples imagens 2D dos cartões de crédito até os sofisticados e interativos aparelhos médicos 3D, evidencia que é possível alcançar técnicas muito além destes aspectos apresentados, em benefício da ciência e da evolução humana. É necessário que a inovação e a tecnologia utilizadas sejam constantemente atualizadas e acompanhem a rápida evolução na área, em sua real contribuição científica. O uso, cada vez mais recorrente, da holografia integrada a contextos reais confirma o caminho natural das imagens virtuais e 3D para uma "existência" fora das telas. É importante ressaltar que há um sentido místico e emocional forte nos hologramas, além do visual, pelo lado metafísico, holístico e metafórico. Ao observar que cada partícula do universo carrega consigo partes de um todo contendo a totalidade dos padrões de probabilidades 2D para um evento real a ser projetado e holografado em 3D, adaptado à existência física, pode-se pensar num caminho sem volta e numa evolução de paradigmas baseados em raciocínios não lineares, numa meta-estrutura de pensamento e de concepção de realidade. O conceito de holograma estabelecido pela física e pela metafísica sobre o "universo holográfico" encaixa-se no contexto de "mundos alternativos", em que a forma não é definida pela matéria. É a consciência que cria a aparência percebida pelo cérebro de nosso corpo e de tudo que interpretamos no campo físico. Flüsser (2007) defende que na época de Platão o mundo era entendido pela "matéria disponível", e hoje, ao contrário, tentamos "materializar" as formas. Esta realidade poderá, em breve, ser incorporada naturalmente a atividades do cotidiano diário, auxiliando sensivelmente o design, as ciências e a existência humana no Cosmos.

\section{Referências}

BOHM, David. 1994. O universo que dobra e desdobra. In: Wilber, K., Pribram, k., Capra, F.et al (Org.). O paradigma holográfico e outros paradoxos. São Paulo: Cultrix.

BOHM, D. 2008. Totalidade e Ordem Implicada: coletânea de textos. São Paulo: Editora Madras.

CAPRA, F. 1996. A Teia da Vida: uma nova compreensão científica dos sistemas vivos.

São Paulo: Ed. Cultrix.

Anais [Oral] do 7º Congresso Internacional de Design da Informação | CIDI 2015

Proceedings [Oral] of the 7th Information Design International Conference / IDIC 2015 
FLÜSSER, V. 2007. O mundo codificado: por uma filosofia do design e da comunicação. São Paulo: Cosac Naify.

HARIHARAN, P. 2002. Basics Holography. Cambridge: Cambridge University Press. HAWKING, S. 2010. The Grand Design. Bantam Books.

LAPLANTINE, F., \& TRINDADE, L. 1997. O que é imaginário. São Paulo: Ed. Brasiliense.

MEDEIROS, A. 2006. A história e a física do fantasma de Pepper. Caderno Brasileiro de Ensino de Física, vol.23, n.3, p.329, dez 2006.

MORIN, E., 1990. Introdução ao pensamento complexo. Lisboa: Instituto Piaget. $2^{a}$ ed.

PINHEIRO, O. 2008. A imagem infográfica: arte, design, semiótica, ciência cognitiva. Anais do 17ํㅡㄹ Encontro Nacional da Associação Nacional de Pesquisadores em Artes Plásticas: Florianópolis: UDESC.

PLAZA, J. E TAVARES, M. 1998. Processos Criativos Com os Meios Eletrônicos: Poéticas Digitais. São Paulo: Editora Hucitec.

PRIBRAM, K. 1977. Languages of the Brain. Monterey, CA:Wadsworth.

PRIBRAM, K. 1994. Qual a confusão que está por toda a parte. In: Wilber, K., Pribram, K.,Capra, F. et al (Orgs.) O paradigma holográfico e outros paradoxos. São Paulo: Cultrix.

SUSSKIND, L. 2006. A paisagem cósmica: A llusão da Teoria das Cordas do Design Inteligente. New York: Hachette Book Group / Back Bay Books.

TALBOT, M. 1991. O Universo Holográfico. Rio de Janeiro: Best Seller.

WILBER, K. et al (Org). 2003. Física, misticismo e o novo paradigma holográfico: uma avaliação crítica. In: O paradigma holográfico e outros paradoxos: uma investigação nasfronteiras da ciência. São Paulo: Editora Cultrix.

\section{Referências eletrônicas}

BELÉNDEZ, A., 2009. Holografía: ciencia, arte y tecnología. Rev. Bras. Ensino Fís. In: Home: <http://www.scielo.br/>, São Paulo abr. 2009, vol.31, no.1, ISSN 1806-1117 In: Home: <http://dx.doi.org/10.1590/S1806-11172009000100011>, 28/02/2015.

DAIBERT, L., 2014. Laboratório de holografia. EBA/UFMG. In: Home: <http://www.eba.ufmg.br/hololab/introducao.html.>, 11/06/2014.

DeFREITAS, 2014. Holo-Gram Newsletter, Vol. 6, No. 2, 1988; and the Laser Arts Society for Education and Research, Vol. IX, No. IV, 1989. In: Home: <http://www.holoworld.com/holo/editorial1.html>, 11/06/2014.

FRANÇA, M., 1988. Holografias: Esculturas de luz. In: Home: Revista Super Interessante. In:Home: <http://super.abril.com.br/tecnologia/holografias-esculturas-luz-438618.shtml>, 27/02/2015.

MAIER, B., 2008. Hologram.ru. Holographic metaphor. B.O. Maier. In: Home: <http://www.holography.ru/files/holmete.htm>. 21/02/2015..

M.I.T. BENTON, 2003. In: Home: <newsoffice.mit.edu/2003/Benton>, 21/02/2015.

M.I.T. MUSEUM, 2015. In: Home: <http://web.mit.edu/museum/collections/holography.html>, $21 / 02 / 2015$.

Anais [Oral] do $7^{\circ}$ Congresso Internacional de Design da Informação | CIDI 2015

Proceedings [Oral] of the 7th Information Design International Conference / IDIC 2015 
MUNDOS FANTÁSTICOS, 2011. Revista Super Interessante, nr 164 - Dezembro de

2011. In: Home: <http://www.mundos-fantasticos.com/ciência/artigos-cientificos /kip-thorneprocuro-a- foto-do-big-bang-/>, 27/02/2015.

PESSOA JR , O., 2015. Universo Holográfico. In: Home: O Universo Holográfico por Pessoa Jr. <http://www2.uol.com.br/vyaestelar/universo_holografico.html>, 28/02/2015.

PRIBRAM, K., 2014. Psychology Today interview - In: Home: <http://archive.org/stream/ HolographicModelOfTheUniverse/holouni_djvu.txt.>, 04/04/2014.

UWEMASS, 2014. Mussion Eyeliner In: Home:<www.musion.co.uk/uwe-maass-on-cnn>, $14 / 04 / 2014$.

\section{Sobre os autores}

Ekaterina E. I. Barcellos, Mestranda, UNESP/ FAAC, Brasil, <kettyinglesis@bol.com.br> Marlon Mercaldi, Mestrando, UNESP/FAAC, Brasil, <marlonmercaldi@hotmail.com>

Olympio J. Pinheiro, Ph.D., UNESP/ FAAC, Brasil <holihn@uol.com.br>

Galdenoro Botura Jr, Ph.D. UNESP/ FAAC, Brasil <galdenoro@gmail.com> 